\title{
Attention and the depth perception of kittens
}

\author{
RICHARD D. WALK, JANE D. SHEPHERD, and DAVID R. MILLER \\ George Washington University, Washington, D.C.
}

\begin{abstract}
An experiment by Held and Hein (1963) in which active kittens discriminated depth and passive ones did not is often cited as showing the importance of self-produced locomotion for perceptual development. We hypothesized that their passive kittens may have paid less attention than active kittens to the environment. We repeated their experiment with kittens that either were given an interesting display to watch or were allowed to move through the environment by lifting their heads to close a microswitch that operated a go-cart. Kittens that paid greater attention to the environment discriminated depth on the visual cliff, whereas those reared with similar light exposure conditions but without the increased attention did not discriminate.
\end{abstract}

A classic experiment by Held and Hein (1963) was designed to show the importance of self-produced movement for perceptual development. They raised kittens in the dark for 8-12 weeks. Kittens were then exposed to the light for $3 \mathrm{~h}$ a day. The active group of kittens actively walked through the environment. Each kitten in this group pulled an animal from the passive group that could look at the same environment, but, because it was in a small box from which its head protruded, could neither walk nor see its limbs. The apparatus is best illustrated in Held (1965). After about 10 days of this treatment, the active kittens developed the visual placing response (i.e., the extension of the forelimbs on approach to a visual surface). Both groups of kittens were then tested on the visual cliff; the active kittens discriminated depth, but the passive ones did not. Except for the $3 \mathrm{~h}$ in the light, all kittens were with their mothers in the dark and were allowed to move freely.

Did passive kittens pay attention to the environment through which they were transported? Our preliminary observations indicated that passive kittens did not.

We repeated the essential condition of Held and Hein's (1963) experiment, but added groups that were "passively exposed," meaning that they could not locomote or see their limbs, but they were reared in a more interesting visual environment. Our purpose was to determine whether passive exposure does not lead to depth discrimination, and whether increased attention to the environment does. We also added a group of kittens reared in the dark until tested and a comparison group of kittens reared in the normal light of the laboratory.

We had two methods of increasing the attention of some of the kittens that were reared as passive animals. The car-watching group watched a toy display with small cars that continuously circled a toy roller coaster. The pas-

This experiment was supported in part by Grant MH-25,864 from the National Institute of Mental Health and by Biomedical Research Support Grant 2-S07-RR07019-14 National Institutes of Health to George Washington University. Requests for reprints should be sent to Richard D. Walk, Department of Psychology, George Washington University, Washington, DC 20052. sive locomotion, or go-cart, group had their restraining holder placed on top of a skateboard. These kittens could move in a circular path by lifting their heads to close a microswitch. These kittens and those in the regular passive group were restrained in the same holders. They were "passive"' in the sense that they could not self-locomote or see their paws or bodies.

\section{METHOD}

\section{Subjects}

The subjects were 47 kittens from 17 litters born and reared in the laboratory. Kittens from each litter were divided among the groups, except for the 8 kittens raised in the light from birth, for whom this was not possible. Of the kittens reared in the dark until 40 days old, 4 were in the active group, 10 in the car-watching group, 4 in the go-cart group, and 11 in the regular passive group. Ten kittens were dark-reared until tested.

\section{Apparatus}

Holders. Figure 1 shows a holder used for all three passive groups. The sides of the holders were made of $1.9-\mathrm{cm}$ pine boards placed on top of a piece of $20 \times 30.5 \mathrm{~cm}$ Masonite. The sides, which were mounted vertically $14.6 \mathrm{~cm}$ apart, measured $21 \mathrm{~cm}$ at the base and $17 \mathrm{~cm}$ at the top, and were $13.3 \mathrm{~cm}$ high. The back of the holder was open, but the front was covered with a $22.2 \times 30.5 \mathrm{~cm}$ piece of Masonite angled back $17^{\circ}$ from the vertical (a $73^{\circ}$ angle) with an opening in the center for the kitten's head. The opening was $6.35 \mathrm{~cm}$ wide and ended in a $\mathrm{V}$ that was $8.9 \mathrm{~cm}$ deep at the sides and $11.4 \mathrm{~cm}$ deep at the low point of the $\mathrm{V}$. The movable Masonite facing was $10.2 \mathrm{~cm}$ wide and $15.2 \mathrm{~cm}$ long with an inverted $V$ that was $3.5 \mathrm{~cm}$ high and $5.7 \mathrm{~cm}$ wide at the base. Along the sides of the Masonite insert were $3-\mathrm{mm}$ slots that were $5.7 \mathrm{~cm}$ long. Holes for bolts, about $3 \mathrm{~mm}$ in diameter and $5.1 \mathrm{~cm}$ long, were on the front piece above the inverted $\mathrm{V}$. This piece permitted the kitten's neck to fit through the opening, and, when lowered and the wing nuts tightened, prevented removal of the head. Once placed inside the box with its head protruding through the opening, a diamond-shaped neck collar, the kitten could look around but not see its paws or body.

Car-watching apparatus. The car-watching apparatus (Animal Coaster, manufactured in Taiwan for Calderon Co., Glen Cove, NY 11542 ) is illustrated in Figure 2. The track was in the shape of a figure 8. Four small toy cars were carried by ratchets up a ramp-like arrangement. They were released at the top to coast down and around the figure 8 and through a tunnel to the base, where they were caught by the ratchets and repeated the cycle. The movement was continuous and somewhat irregular. The apparatus measured about $19 \mathrm{~cm}$ high $\times 57 \mathrm{~cm}$ long $\times$ $38 \mathrm{~cm}$ wide. As Figure 2 shows, the kitten was afforded a close view of the entire apparatus. With continuous operation day after day, the cheap motors wore down. We used four Animal Coasters and had to 


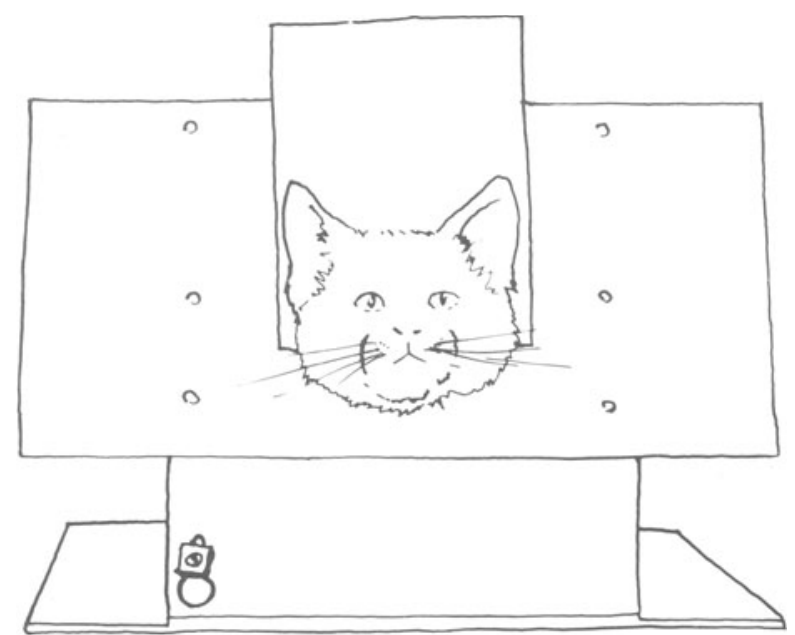

Figure 1. A kitten in the passive holder. It cannot see its limbs or body, but it can look around.

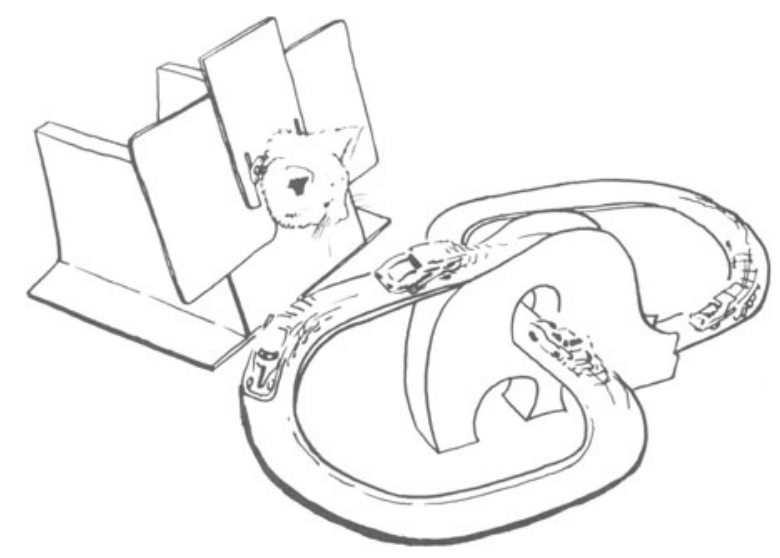

Figure 2. A kitten in the passive holder observing cars moving along the coaster track.

substitute a Merry-Go-Zoo (Tomy No. 1028, 901 E. 233rd St., Carson, CA 90745) for the last 3 kittens. In this display, a toy giraffe loaded a toy onto the train in the presence of twirling toy penguins. Both of the displays induced intense tracking by the head and eyes of the kittens that lasted for the entire 3-h period.

Go-cart. The passive-locomotion apparatus (see Figure 3) was the holder described above, but it was mounted on a skateboard that was attached by an iron arm to a motor, around which it turned on a circular path. ${ }^{1}$ The rigid iron arm was mounted perpendicularly to the side of the holder, and it extended to a motor to which it was attached with a clamp. The iron arm was $51 \mathrm{~cm}$ long, and the center of the box $9.2 \mathrm{~cm}$ away from it so that the radius of the go-cart was about $60 \mathrm{~cm}$; thus, the circumference of the circular route traversed by the kitten was about $3.8 \mathrm{~m}$ long.

The protruding arm of a microswitch was padded with tape and placed directly above the kitten's head. The microswitch was attached to a screw that permitted the switch to be adjusted in height for each kitten, so the switch closed only if the kitten raised its head. When the switch was closed, the go-cart moved forward; if the kitten lowered its head, the switch opened and the go-cart stopped. Some of the kittens achieved good control of the go-cart and made several hundred revolutions during the 3-h period.

Exposure environment. This environment was for the active, passive, and car-watching kittens. The environment was a sheet metal cylinder, $127 \mathrm{~cm}$ in diameter and $55 \mathrm{~cm}$ high, divided into two equal sections by a piece of sheet metal placed across the diagonal. The plywood floor had $1.9-\mathrm{cm}$-wide black and white stripes, and the walls were partly covered with a geometric design on cloth with red, blue, orange, and green figures on a white background.

When an active animal was in this environment, chicken wire netting, made rigid with a wooden backing frame, was placed on top to prevent the kitten from jumping out.

Visual cliff. The visual cliff used for the present study is illustrated in Walk (1966). It was a large glass-topped "table" $1.83 \mathrm{~m}$ wide $\times$ $2.44 \mathrm{~m}$ long $\times 1.02 \mathrm{~m}$ high. A center board bisected the glass into approximately equal segments $1.83 \times 1.22 \mathrm{~m}$. A patterned cloth surface $(2.2-\mathrm{cm}$ red and white checks) was under the glass of one side, the shallow side, and the same patterned surface was some distance below the glass on the deep side. The surface on the deep side could be raised or lowered by a jack-like arrangement. The deep-side pattern was placed 47,30 , or $23 \mathrm{~cm}$ below the glass. The apparatus was enclosed by a 20 $\mathrm{cm}$-high border to keep the subject from falling or leaping off. Lights, controlled by a rheostat under the center board, permitted equal illumination of the two sides. Overhead illumination was diffused through cloth sheets to minimize reflections. The center board was $1.8 \mathrm{~m}$ long, $14 \mathrm{~cm}$ wide, and $6 \mathrm{~cm}$ above the glass.

\section{Procedure}

The experimental procedure for the active, passive, car-watching, gocart, and dark-reared kittens was the same until 40 days after birth; all were reared in the dark until then. Dark-reared animals remained in the dark. The other groups began $3 \mathrm{~h}$ of light exposure each day for 10 days, and initial testing began 49 days after birth. Testing followed $3 \mathrm{~h}$ of light exposure. Normal animals remained in the laboratory colony in the light.

During the 10 days of $3 \mathrm{~h} /$ day light exposure, (1) active animals were allowed free run of one-half of the circular exposure environment; (2) passive kittens remained in holders, by themselves, within the exposure environment; ${ }^{2}(3)$ car-watching animals were with the animal coaster apparatus, running continuously, in the exposure environment; and (4) go-cart kittens were in one corner of a large room.

\section{Testing}

Visual cliff. On the first day of testing, the kittens were placed on the visual cliff twice, 12 trials each time, with a $47-\mathrm{cm}$ visual depth. The next day they were tested at $47 \mathrm{~cm}$, and, if 9 or more of the 12 descents were to the shallow side, they were tested at the $30-\mathrm{cm}$ visual depth until 9 shallow responses were made, and then at the $23-\mathrm{cm}$ visual depth until 9 shallow responses were made. A kitten could move through the entire sequence $(47,30$, and $23 \mathrm{~cm}$ depths) on 1 day, but only 2 kittens did (1 normal and 1 car-watching kitten).

The kittens were tested on Days 50, 52, 54, 56, 59, 64, and 69 after birth, counted as Days 1, 3, 5, 7, 10, 15, and 20. Day 49 was not counted as a testing day. Kittens not reaching criterion on a portion of the testing sequence were counted as achieving it on Day 74, 25 days after testing started.

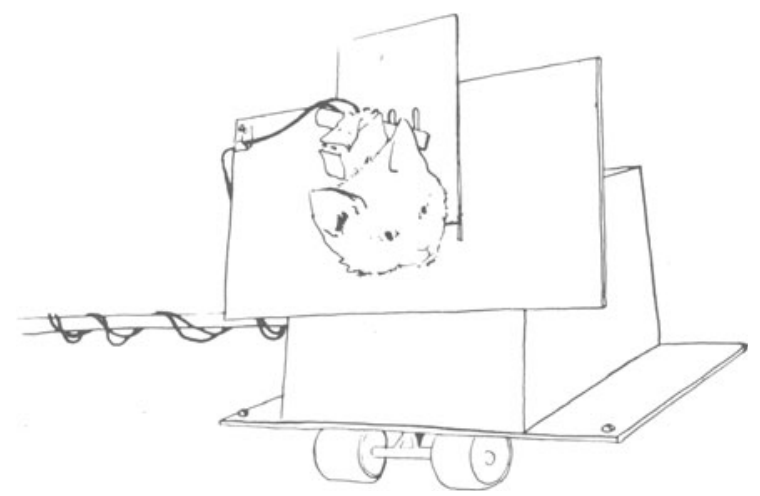

Figure 3. A kitten in the passive holder mounted on a skateboard. The kitten can lift its head to close the switch, thus moving the skateboard forward in a circle; lowering the head stops the skateboard. 
Kittens were kept in the dark except for $4 \mathrm{~h}$ a day spent in the semicircular environment, after which they were tested, if a testing day.

Other measures. Other measures were the following: (1) Visual following response-The experimenter held up a small object and watched the kitten's eyes. The object was moved slowly to see if the eyes followed it. (2) Visual placing response-The kitten was held by the torso with forelimbs free, and brought slowly forward and down toward a table top. Visual placing was positively scored when the paws were extended toward the surface before contact. With lack of visual placing, the paws remained flaccid. (3) Guided visual placing response-The kitten was brought forward toward a serrated surface with one forelimb free. A positive response meant that the kitten reached for the protruding prong; a negative response meant that hits were random (Hein \& Held, 1967). (4) Eyeblink response-The experimenter moved a hand toward the kitten's eyes without touching the kitten and noted whether the kitten blinked its eyes.

A kitten was given three to five tests on each measure per testing day. A positive score meant that the response was elicited on most tests.

\section{RESULTS}

\section{Visual Cliff}

The important comparison is between the regular passive group and the two attention groups, the car-watching and go-cart kittens. More shallow-side descents were observed on the first test at $47 \mathrm{~cm}$ for the attention than for the passive kittens (Mann-Whitney $U=34, p<.05$, one-tailed): averages were 7.1 shallow descents (in 12 trials) for the passive kittens and 9.2 for the car-watching kittens. Gocart kittens averaged 8.0 shallow descents, which was not significantly different from descents of passive kittens.

The number of days of testing to reach criterion at the $47-\mathrm{cm}$ visual depth varied among groups (see Figure 4).
Figure 4 shows that the regular passive and the darkreared kittens form one group, and the normal, carwatching, go-cart, and active kittens form a second group. An unequal- $N$ analysis of variance with the Studentized range statistic to assess differences between means showed that the regular passive group took significantly longer to reach criterion $(p<.01)$ at $47 \mathrm{~cm}$ than did carwatching and go-cart kittens. This is the crucial comparison. The dark-reared kittens were also significantly slower $(p<.01)$ than the attention groups, as expected. Days to criterion at the lesser depths $(30 \mathrm{~cm}$ and $23 \mathrm{~cm})$ confirm the same result.

A study of Figure 4 reveals an anomaly. The normal kittens averaged almost 14 days to reach criterion at the 23-cm depth, far longer than the active and attention groups. Normal kittens were reared in the light-dark cycle of the laboratory. After a few days of testing at the 23cm depth, they no longer acted as "proper" subjects. They jumped playfully on stiff legs, lay down on the center board, and rolled off. Adapted to the visual environment, they seemed to regard the $23-\mathrm{cm}$ depth as a play situation.

Latencies of the various passive groups differed markedly on the first testing day. Average latency of descent, with a ceiling at $60 \mathrm{sec}$, was $9.2 \mathrm{sec}$ for go-cart kittens $(n=4), 27.6 \mathrm{sec}$ for car-watching kittens $(n=9$ available), and $45.2 \mathrm{sec}$ for passive kittens ( $n=6$ available). The means were all significantly different from each other $(p<.01)$ on the Studentized range statistic. The rapid motion of the go-cart seems to have been transferred to its kittens when they could first walk in the light.

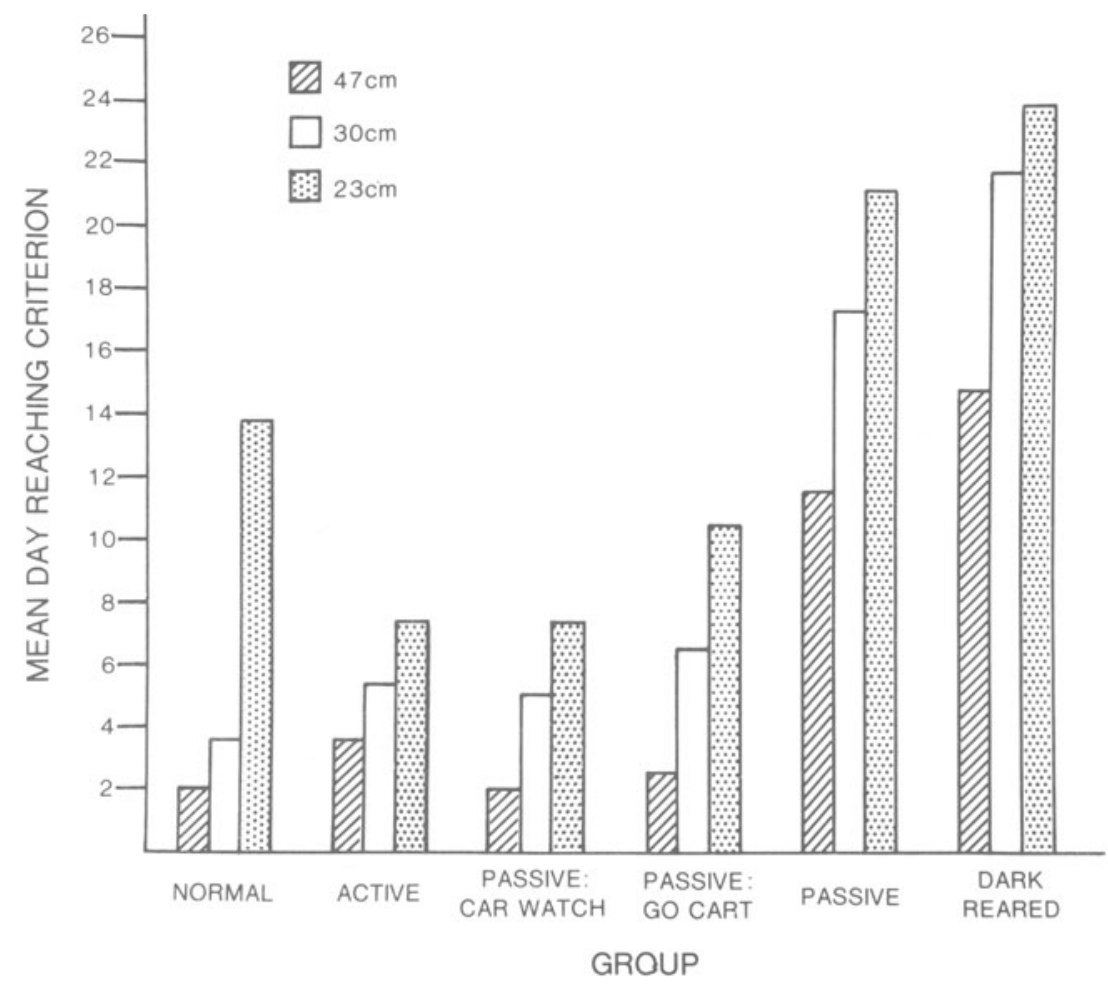

Figure 4. Average testing day when kittens in each group reached a criterion of 9 of 12 responses to the shallow side of the visual cliff at the three visual depths. 
Table 1

Testing Day When the Groups Acquired Four Visual Behaviors

\begin{tabular}{lccccc}
\hline \multicolumn{1}{c}{ Group } & & $\begin{array}{c}\text { Visual } \\
\text { Following }\end{array}$ & $\begin{array}{c}\text { Visual } \\
\text { Placing }\end{array}$ & $\begin{array}{c}\text { Guided Visual } \\
\text { Placing }\end{array}$ & Eyeblink \\
\hline Car-Watching & $10^{*}$ & 1.8 & 2.2 & 4.6 & 7.8 \\
Go-Cart & 4 & 3.5 & 3.5 & 4.0 & 11.3 \\
Regular Passive & 7 & 5.0 & 5.3 & 9.3 & 11.3 \\
Dark-Reared & 6 & 10.8 & 11.2 & 15.0 & 15.0 \\
\hline * & & &
\end{tabular}

*Only 8 car-watching kittens were tested for guided visual placing.

\section{Other Measures}

As shown in Table 1, the large and significant differences observed between the regular passive kittens and the two groups of attention animals on the visual cliff were not found for the acquisition of visual following, visual placing, guided visual placing, and eyeblink to an approaching object. The dark-reared kittens were significantly different from the other groups $(p<.05$ or better) on everything except eyeblink reaction to an approaching object, where no groups differed significantly. Passive kittens differed from attention animals on no measures.

\section{DISCUSSION}

Two points concerning this experiment are discussed here: (1) the operation of attention, and (2) the relation between this experiment and studies that show benefits of crawling experience for human infants.

The prismatic adaptation experiments by Held and his coworkers (summarized in Held, 1965) found that self-produced motion helped subjects adapt to prismatic displacement, and passive exposure did not, whereas other investigators found adaptation when information about the prismatic discordance was provided to subjects (reviewed in Lackner, 1981; Welch, 1978). Held and Hein (1963) found that self-produced locomotion was necessary for their kittens to discriminate depth, but our kittens, without locomotion, discriminated depth when their attention to the environment was increased.

The theoretical viewpoint of Gibson $(1966,1979)$ is most helpful here. Gibson stressed the importance of motion for discerning the invariant relationships of the perceptual environment. The kitten in the carwatching group moves its head to watch the cars, and all of the invariant perceptual relations of this environment cross in front of its eyes. Because the environment changes, the car-watching kitten is motivated to see, as is the go-cart kitten, and movement of the head and eyes reveals a world in depth. The go-cart kitten lifts its head to close a microswitch and make the cart move, and lowers its head to stop the cart. The environment changes as a function of its control. When these kittens are placed on the visual cliff, movement of the head and eyes reveals the different depths of the two sides. On the other hand, passive kittens in a stable environment are not motivated to look, and the perceptual variations in the environment remain undiscovered. Thus, the attention of the kitten to the environment is important, not whether the kitten actively walks through it.

Experiments about the crawling experience of human infants (Berenthal \& Campos, 1987; Berenthal, Campos, \& Barrett, 1984) require an explanation of depth perception in the visual cliff situation. In the kitten experiments, the kitten is placed on the centerboard of the visual cliff, and the experimenter stands behind the kitten at the bisection of the shallow and deep sides so as not to influence which side the kitten chooses. To get off the center board, the kitten discriminates depth (goes predominantly to the shallow side) or does not (goes as often to the deep as to the shallow side). In my studies (Walk, 1969) of human infants, as an analogous situation to that of kittens, the infant is placed on a centerboard that progressively narrows. The infant is placed on the wide end by an experimenter, and the mother calls from the narrow end. The infant can go to the mother over either the shallow or the deep side; because the board narrows, the infant must make a "choice," but the mother does not coax the child to either side. With the bisection condition, the infants spontaneously chose the shallow side on over $90 \%$ of the trials, even for visual depths of $25 \mathrm{~cm}$; however, at the visual depth of $25 \mathrm{~cm}$, over $38 \%$ of the infants were coaxed to the mother over the deep side, and younger infants, presumably with less crawling experience, were coaxed there $65 \%$ of the time, whereas older ones, more experienced in crawling, were coaxed there only $21 \%$ of the time.

In the studies cited by Berenthal and Campos (1987), the mother coaxed the baby from the deep side. Infants with crawling experience were less likely to be coaxed by mother to cross the "deep" end than infants with little crawling experience. However, the cited analogy to Held and Hein's (1963) kittens is weak because the kittens were given a choice of shallow or deep sides, whereas human infants were lured. In all probability, given a situation comparable to the kitten one (as in the bisection condition), the infants with more crawling experience would choose the shallow side no more frequently than those with little crawling experience. Our experiment, like Held and Hein's, demonstrates the development of depth perception; those cited by Berenthal and Campos show the acquisition of the fear of depth. Human infants have differentiated the perceptual environment through their attention to it long before they begin to crawl; locomotion adds an emotional component to some aspects of depth perception.

\section{REFERENCES}

Berenthal, B. I, \& Campos, J. J. (1987). New directions in the study of early experience. Child Development, 58, 560-567.

Berenthal, B. I., Campos, J. J., \& Barrett, K. C. (1984). Selfproduced locomotion: An organizer of emotional, cognitive, and social development in infancy. In R. Emde \& R. Harmon (Eds.), Continuities and discontinuities in development (pp. 175-210). New York: Plenum Press.

GrBson, J. J. (1966). The senses considered as perceptual systems. Boston: Houghton Mifflin.

GrBson, J. J. (1979). The ecological approach to visual perception. Boston: Houghton Mifflin.

HeIN, A., \& HeLD, R. (1967). Dissociation of the visual placing response into elicited and guided components. Science, 158, 390-392.

Held, R. (1965). Plasticity in sensory-motor systems. Scientific American, 213(5), 84-94.

HelD, R., \& Hein, A. (1963). Movement produced stimulation in the development of visually guided behavior. Journal of Comparative \& Physiological Psychology, 56, 872-876.

LACKNER, J. R. (1981). Some aspects of sensory-motor control and adaptation in man. In R. D. Walk \& H. L. Pick, Jr. (Eds.), Intersensory perception and sensory integration (pp. 143-173). New York: Plenum Press.

WALK, R. D. (1966). The development of depth perception in animals and human infants. Monographs of the Society for Research in Child Development, 31(107), 82-108.

WALK, R. D. (1969). Two types of depth discrimination by the human infant with five inches of visual depth. Psychonomic Science, 14, 253-254.

WELCH, R. B. (1978). Perceptual modification: Adapting to altered sensory environments. New York: Academic Press.

\section{NOTES}

1. We are indebted to Michael Schwartz for constructing the movable bearing-like arrangement that supplied power to the go-cart when the switch was closed, and repeated revolutions did not entangle the electrical cord.

2. The first car-watching kitten was exposed with a regular passive kitten in the other half of the circular environment. The continual sound from the car-watching apparatus kept the regular passive kitten alert and looking around during the entire 3-h period, and, at the end of 10 days of such exposure, this animal tested like a car-watching kitten. The kitten was kept in the regular passive group, diminishing its effect, but all other regular passive kittens were exposed without distracting noise from the car-watching or go-cart kittens.

(Manuscript received for publication September 2, 1987.) 